\title{
Mg/Al layered double hydroxide-Pt nanoparticle composite by delamination-restacking route
}

\author{
Nityashree. $\mathbf{N} \cdot$ Premitha Menezes
}

Received: 4 March 2012/ Accepted: 25 May 2012/Published online: 14 June 2012

(C) The Author(s) 2012. This article is published with open access at Springerlink.com

\begin{abstract}
Platinum nanoparticle intercalated magnesiumaluminum layered double hydroxide (LDH) composite was prepared by restacking the colloidal dispersion of organically modified LDH in the presence of preformed oleylamine capped platinum nanoparticles in $n$-butanol. The resultant nanocomposite was characterized using powder X-ray diffraction (PXRD), infrared (IR) spectroscopy, transmission electron microscopy (TEM), selected area electron diffraction and energy dispersive X-ray spectroscopy (EDX). The PXRD pattern of the composite indicates an expanded interlayer due to the intercalation of the Ptnanoparticles into the LDH interlayer region. PXRD patterns along with the IR spectra confirm the formation of the precursors and the composite. TEM image of Pt-nanoparticles shows spherical particles with an average particle size of $\sim 3 \mathrm{~nm}$ and that of the composite shows dispersed Pt-nanoparticles on the LDH matrix. The presence of Pt, $\mathrm{Mg}$ and $\mathrm{Al}$ in the composite is indicated in the EDX data.
\end{abstract}

Keywords Layered double hydroxide .

Delamination-restacking · Capped Pt-nanoparticles .

Nanocomposite

\section{Introduction}

Metal nanoparticle supported layered solid composites are gaining immense attention for their application as catalysts (Choudary et al. 2000; Huu et al. 2000, Gérardin et al.

Nityashree. N $(\square) \cdot$ P. Menezes

Materials Research Group, Department of Chemistry,

St. Joseph's College, 36 Lalbagh Road,

Bangalore 560 027, India

e-mail: n.nityashree@gmail.com
2005), optically tunable materials (Smith et al. 2001), energy conversion devices (Granqvist 2007), sensors (Trudeau 2007; Liu et al. 2012), photocatalysts (Nosaka 2011), etc. Layered solid-nanoparticle composites are generally prepared by impregnation (Komiyama 1985), coprecipitation (Basile et al. 2000), ion-exchange (Rajamathi et al. 2009) and sonochemical (Belova et al. 2008) methods. The composites prepared by the conventional wet impregnation method are not fully reproducible and give rise to an inhomogeneous distribution of the metal nanoparticles on the surface (Komiyama 1985). Composites prepared by co-precipitation in the presence of the noble metals show phase segregation on heating and the size of the metal particles formed were large (Basile et al. 2000). A few composites prepared by growing nanoparticles in the interlayers of the supporting materials show uncontrolled particle growth and an inhomogeneous distribution of the nanoparticles (Xu et al. 2009; Wang et al. 2002). An alternate and more effective way of synthesizing layered solid-nanoparticle composites is by delamination of layered solid to obtain a colloidal suspension of monolayers followed by restacking the layers in the presence of preformed nanoparticles. Nanocomposites prepared starting from monodispersed capped nanoparticles and delaminated layers were found to have uniformly distributed nanoparticles and tunable optical property (Venugopal et al. 2006a). Homogeneity in the distribution of the nanoparticles in the composites occurs as a consequence of the components being mixed at the level of individual delaminated layers.

The method of synthesis, size and distribution of the nanoparticles in a matrix plays an important role in the stability and activity of a catalyst (Peralta et al. 2011; Yeung et al. 1997). The activity is high for smaller sized particles due to large surface area resulting in a larger number of active sites 
(Zhang et al. 2005). The stability of the nanoparticles decreases with their size as they tend to agglomerate to give rise to particles of larger sizes. Capping agents are employed to stabilize the nanoparticles (Amstad et al. 2009) and dispersing nanoparticles on various supports is believed to further stabilize the nanoparticles (Papp et al. 2001). Dispersion of nanoparticles over layered materials is achieved by using delaminated layers as some reports emphasize on twodimensional layers being used as building blocks to composites through various solution-phase processes (Ma and Sasaki 2010). Delamination or exfoliation of smectites (Walker 1960) and various other layered solids such as chalcogenides (Lerf and Schöllhorn 1977), metal phosphonates (Yamamoto et al. 2001), layered metal oxides (Nazar et al. 1991), layered double hydroxide (LDH) (Pagano et al. 2000), $\alpha$-metal hydroxides (Nethravathi et al. 2005) and layered hydroxy salts (Rajamathi et al. 2005) have been reported.

Layered double hydroxides are anionic clays with positively charged metal hydroxide layers and charge compensatory interlayer anions. Their general formula is $\left[\mathrm{M}_{1-x}^{2+}\right.$ $\left.\mathrm{M}_{x}^{\prime 3+}(\mathrm{OH})_{2}\right]^{x+}\left(\mathrm{A}^{n-}\right)_{\mathrm{x} / n} \quad\left(\mathrm{M}=\mathrm{Mg}^{2+}, \quad \mathrm{Co}^{2+}, \quad \mathrm{Ni}^{2+}\right.$, etc; $\mathrm{M}^{\prime}=\mathrm{Al}^{3+}, \mathrm{Cr}^{3+}, \mathrm{Fe}^{3+}$, etc; $0.2 \leq x \leq 0.33 ; \mathrm{A}^{n-}=$ anions with charge ' $n$ ') (Trifiro and Vaccari 1996). LDHs are used as solid-base catalysts (Amstad et al. 2009), catalyst supports (Papp et al. 2001) and precursors to catalysts (Trifiro and Vaccari 1996). LDH-metal composite catalysts are multifunctional materials with metal, acid and basic sites exhibiting metal-support interactions as shown by Kazanski et al. (1997). LDHs with organically modified interlayers were found to undergo delamination in organic solvents like 1-butanol, toluene, formamide, etc. (Pagano et al. 2000; Jobbágy and Regazzoni 2004; Hibino and Jones 2001).

Nanoparticles are known to exhibit various size dependent properties that are different from that of the bulk. As the particle size decreases, the particles are known to show high activity but are quite unstable at the same time. These properties can be exploited only when the nanoparticles are stabilized by some method. Stabilization of surface active nanoparticles by embedding them in layered materials is one of the techniques. Platinum nanoparticles and Pt-based composites are used as catalysts (Anumol et al. 2011), photocatalysts (Taing et al. 2011), electrocatalysts (Habibi and Delnavaz 2010), sensors (Yang et al. 2008), etc. On the other hand, $\mathrm{Mg} / \mathrm{Al} \mathrm{LDH}$ due to its easy availability and tunable composition makes them important supports in various noble-metal based nanocomposites. Among LDHs, $\mathrm{Mg} / \mathrm{Al}-\mathrm{LDHs}$ are interesting due to their wide applications, low toxicity, ease of formation and their economic viability. Generally, LDHs are available in the carbonated form because of ubiquitous nature of $\mathrm{CO}_{2}$. Carbonated form of LDH is thermodynamically most stable because of high charge on carbonate ion and the interlayer site symmetry of the LDH matches well with that of the carbonate $\left(D_{3 h}\right.$ symmetry) ion. But carbonated LDHs do not have many applications due to the inertness of the carbonate anion in the interlayer. In order to make the LDHs application oriented one needs to modify the interlayer with other anions like nitrate, chloride, sulfate or organic anions like acetate, formate, surfactants, etc. Platinum nanoparticles have special properties which sets them apart from the other metal nanoparticles as discussed above. Compositing both, $\mathrm{Mg} / \mathrm{Al} \mathrm{LDH}$ and $\mathrm{Pt}$ nanoparticles would synergize the properties of both the materials, thereby making them more application oriented. In this work, we report the synthesis of metal nanoparticle dispersed layered solid composite making use of preformed oleylamine (OA) capped $\mathrm{Pt}$ nanoparticles and dodecyl sulfate (DS) modified $\mathrm{Mg} / \mathrm{Al}$ LDH (hereafter referred to as Pt np-Mg/Al-DS LDH) by delamination-restacking method in $n$-butanol.

\section{Experimental}

$\mathrm{Mg}\left(\mathrm{NO}_{3}\right)_{2} \cdot 6 \mathrm{H}_{2} \mathrm{O}, \mathrm{Al}\left(\mathrm{NO}_{3}\right)_{3} \cdot 9 \mathrm{H}_{2} \mathrm{O}$, sodium dodecyl sulfate (SDS; $\mathrm{CH}_{3}\left(\mathrm{CH}_{2}\right)_{11} \mathrm{OSO}_{3} \mathrm{Na}$ ), $25 \%$ ammonia solution (specific gravity $=0.91$ ), toluene, methanol, oleic acid, $\mathrm{NaBH}_{4}$ and acetone were obtained from Merck India Pvt. Ltd. $\mathrm{H}_{2} \mathrm{PtCl}_{6} \cdot 6 \mathrm{H}_{2} \mathrm{O}$ and oleylamine $\left(\mathrm{OA} ; \mathrm{CH}_{3}\left(\mathrm{CH}_{2}\right)_{7}\right.$ $\left.\mathrm{CH}=\mathrm{CH}\left(\mathrm{CH}_{2}\right)_{8} \mathrm{NH}_{2}\right)$ were procured from Ranchem India Pvt. Ltd. and Sigma Aldrich respectively. All solutions were prepared using Type-II water (specific resistance $15 \mathrm{M} \Omega \mathrm{cm}$, Millipore $^{\mathrm{TM}}$ Elix-3 water purification system) and dissolved $\mathrm{CO}_{2}$ was expelled by boiling the water for $10 \mathrm{~min}$.

\section{Preparation of $\mathrm{Mg}_{2} \mathrm{Al}(\mathrm{OH})_{6} \mathrm{DS} \cdot 2 \mathrm{H}_{2} \mathrm{O}-\mathrm{LDH}$ (Mg/Al-DS LDH)}

Dodecyl sulfate (DS) intercalated $\mathrm{LDH}, \mathrm{Mg}_{2} \mathrm{Al}(\mathrm{OH})_{6}$ DS $2 \mathrm{H}_{2} \mathrm{O}$ (hereafter referred to as Mg/Al-DS LDH) was prepared by coprecipitation. In a typical experiment, metal nitrate mixture of $\mathrm{Mg}^{2+}$ and $\mathrm{Al}^{3+}$ with a molar ratio of $2: 1$ was added drop wise into $50 \mathrm{ml} 1 \mathrm{M}$ ammonia solution which contains six times excess of the stoichiometric amount of SDS with continuous stirring. The slurry was aged for $18 \mathrm{~h}$ at $65{ }^{\circ} \mathrm{C}$ in an air oven. The solid was washed free of ions with hot decarbonated water six to seven times, twice with acetone and dried at $65^{\circ} \mathrm{C}$ overnight.

\section{Preparation of oleylamine capped platinum nanoparticles (OA-capped Pt-nps)}

OA-capped Pt-nps were prepared by a method reported elsewhere with slight modifications (Halder and Ravishankar 2006). A mixture of $500 \mathrm{mg}$ of $\mathrm{H}_{2} \mathrm{PtCl}_{6} \cdot 6 \mathrm{H}_{2} \mathrm{O}$, 
$660 \mathrm{ml}$ toluene, $5 \mathrm{ml}$ oleic acid was refluxed for $6 \mathrm{~h}$ and left undisturbed for $16 \mathrm{~h}$. $192 \mathrm{mg}$ of $\mathrm{NaBH}_{4}$ in $40 \mathrm{ml}$ methanol was added drop wise to the reaction mixture. The solution was allowed to stand at room temperature for 1 hour. Additional $20 \mathrm{mg}$ of $\mathrm{NaBH}_{4}$ was added directly to the reaction mixture and was left undisturbed overnight. The brownish-black solid formed was separated by centrifugation, washed with acetone (3-4 times) and dried in air at $65^{\circ} \mathrm{C}$.

\section{Preparation of oleylamine Pt nanoparticles-Mg/Al-DS LDH (Pt-np-Mg/Al-DS LDH) composite}

$100 \mathrm{mg}$ of $\mathrm{Mg} / \mathrm{Al}-\mathrm{DS} \mathrm{LDH}$ was delaminated in $150 \mathrm{ml}$ 1-butanol by sonicating $(35 \mathrm{kHz})$ at $70{ }^{\circ} \mathrm{C}$ for $2 \mathrm{~h}$. Simultaneously, $10 \mathrm{mg}$ of OA-capped Pt-nps were dispersed in $50 \mathrm{ml}$ of 1 -butanol by sonication at $70{ }^{\circ} \mathrm{C}$ for $30 \mathrm{~min}$. The two dispersions were mixed and sonicated for another hour. The solvent was evaporated using a rotatory evaporator at $80{ }^{\circ} \mathrm{C}$. The solid composite thus obtained was washed with acetone to remove remnant butanol and was dried in an air oven at $65^{\circ} \mathrm{C}$.

\section{Characterization}

The powder X-ray diffraction (PXRD) patterns of the samples were recorded on a Philips X'Pert Pro diffractometer fitted with secondary graphite monochramator ( $\mathrm{Cuk} \alpha$ radiation, $\lambda=1.5418 \AA$ ). The data was collected at the rate of $2^{\circ}$ $2 \theta$ per minute over the $2 \theta$ range $2-70^{\circ}$. Infrared (IR) spectra of the samples were collected using Nicolet IR200 FT-IR spectrometer ( $\mathrm{KBr}$ pellet method, $4 \mathrm{~cm}^{-1}$ resolution). The composite and the platinum nanoparticles were also characterized using Tecnai F30 transmission electron microscopy (TEM) interfaced with energy dispersed X-ray spectroscopy (EDS). Samples for TEM were prepared by dispersing a small amount of the solid in about $10 \mathrm{ml}$ of acetone by sonication, a drop of which was spotted on a carbon coated grid and dried at room temperature.

\section{Results and discussions}

Figure 1a shows the PXRD pattern of the as synthesized oleylamine capped Pt-nanoparticles in which the (111), (200) and (220) reflections of platinum were seen at $2 \theta$ values of $40.08(d=2.265 \AA), 46.45(d=1.962 \AA)$ and $67.75^{\circ} \quad(d=1.1826 \AA)$, respectively (ICSD Number 64917). The structure of platinum nanoparticles corresponds to face-centered cubic with a space group of $\mathrm{Fm} 3 \mathrm{~m}$ (Wyckoff 1963). Furthermore, the average particle size of the oleylamine capped Pt-nanoparticles calculated using
Scherrer's equation was found to be $\sim 5.5 \mathrm{~nm}$. Figure $1 \mathrm{~b}$ shows the PXRD pattern of dodecyl sulfate anion $\left(\mathrm{DS}^{-}\right)$ intercalated $\mathrm{Mg} / \mathrm{Al}-\mathrm{LDH}$. The interlayer distance of $\mathrm{Mg}$ / Al-DS LDH (calculated from the position of the first basal reflection) was found to be $23.9 \AA$ indicating the presence of $\mathrm{DS}^{-}$anion in the interlayer region of the $\mathrm{LDH}$ with the alkyl chains of the surfactant arranged parallel to the crystallographic $c$ axis (Guo et al. 2005) and perpendicular to the layers. In addition to the basal reflections, sawtoothshaped reflections of the $(h O l)$ and $(O \mathrm{kl})$ planes were also seen at $2 \theta$ value in between $35-36^{\circ}$ and $\sim 61^{\circ}$ indicating turbostraticity in the layered solids (Warren and Bodenstein 1965). The PXRD pattern of Pt-np-Mg/Al-DS LDH composite (Fig. 1c) shows reflections due to both the LDH and Pt-nanoparticles (reflections due to platinum nanoparticles are visible in the enlarged inset). The interlayer distance of the Pt-np-Mg/Al-DS LDH composite was found to be $27.6 \AA$. The increase in the interlayer distance of the composite when compared to the $\mathrm{Mg} / \mathrm{Al}-\mathrm{DS} \mathrm{LDH}$ precursor is due to the incorporation of the Pt-nanoparticles into the interlayer region of the $\mathrm{LDH}$, which is in line with an earlier report that showed the increase in the interlayer distance due to incorporation of $\mathrm{CdSe}$ nanoparticles (Venugopal et al. 2006a). The increase in the interlayer distance of the composite due to the intercalation of the OA-capping agent as the positively charged OA-surfactant ions (excluding the Pt-nanoparticle entity) are ruled out as it is unfavorable. The increase in the interlayer distance of

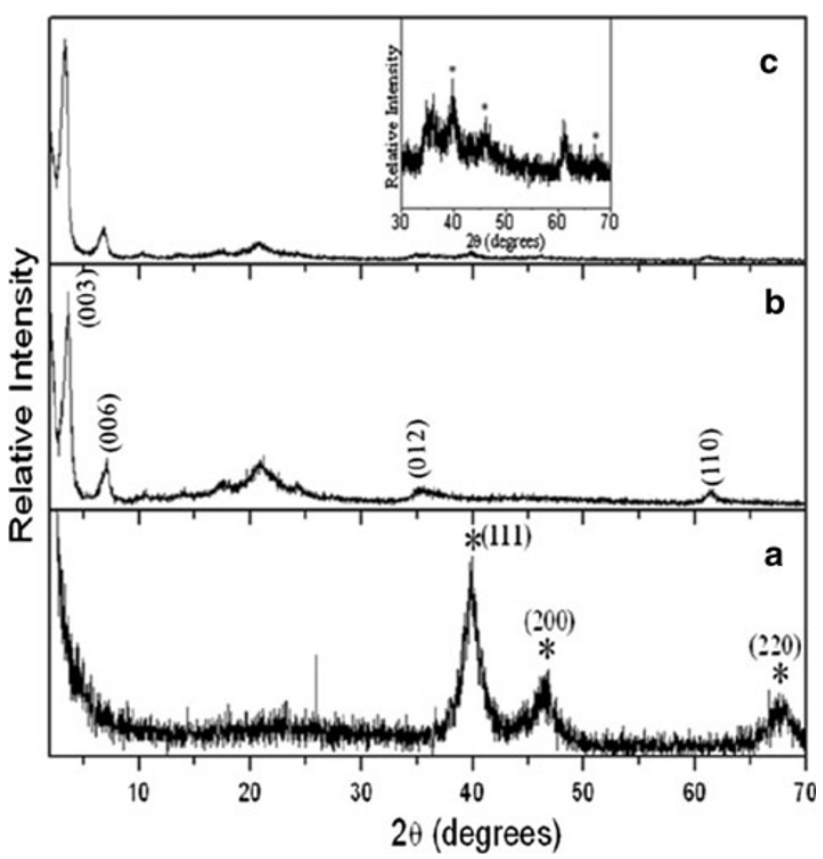

Fig. 1 PXRD pattern of OA-capped Pt-nps (a), Mg/Al-DS LDH (b) and Pt-np-Mg/Al-DS LDH composite (c). Inset shows an enlarged portion of $\mathbf{c}$ from $2 \theta 30^{\circ}$ to $70^{\circ}$. Reflections due to Pt-nanoparticles are marked with asterisk 
the composite due to swelling also can be ruled out as the samples were dried in an air oven at $65{ }^{\circ} \mathrm{C}$ to constant weight driving out the intercalated solvent molecules. Restacking of surfactant intercalated LDHs has been standardized in various solvents and the $d$-spacing of the LDHs got after restacking was found to be very close to the parent LDHs as reported by Venugopal et al. (2006b).

Figure 2 shows the IR spectra of Mg/Al-DS LDH, OAcapped Pt-nps and Pt-np-Mg/Al-DS LDH composite. The IR spectrum of Mg/Al-DS LDH (Fig. 2a) shows bands due to the stretching and bending modes of hydrogen bonded $-\mathrm{OH}$ groups of the hydroxide slabs and the adsorbed and intercalated water molecules at $\sim 3,500$ and $\sim 1,640 \mathrm{~cm}^{-1}$ respectively. Bands due to $\mathrm{C}-\mathrm{H}$ stretching vibrations of the surfactant alkyl chains are seen at 2,853, 2,919 and $2,950 \mathrm{~cm}^{-1}$ suggesting an all-trans conformation (Snyder et al. 1982; MacPhail et al. 1984) and a band due to $\mathrm{S}=\mathrm{O}$ stretching vibrations at $1,222 \mathrm{~cm}^{-1}$ of sulfate polar head of the surfactant were also observed. The all-trans conformation of the surfactant alkyl chain suggests that these chains are linear without bends and twists and this correlates well with the basal spacing observed in the XRD pattern (Fig. 1b). The IR spectrum of the OA-capped Ptnps (Fig. 2b) showed bands due to $\mathrm{NH}$ stretching and bending modes at 3,435 and $1,600 \mathrm{~cm}^{-1}$, respectively. The bands due to $\mathrm{C}-\mathrm{H}$ stretching vibrations of the oleylamine chain appeared between 2,829 and $2,980 \mathrm{~cm}^{-1}$. The IR spectrum of the composite (Fig. 2c) is identical to that of $\mathrm{Mg} / \mathrm{Al}-\mathrm{DS} \mathrm{LDH}$ except for a slight broadening at around

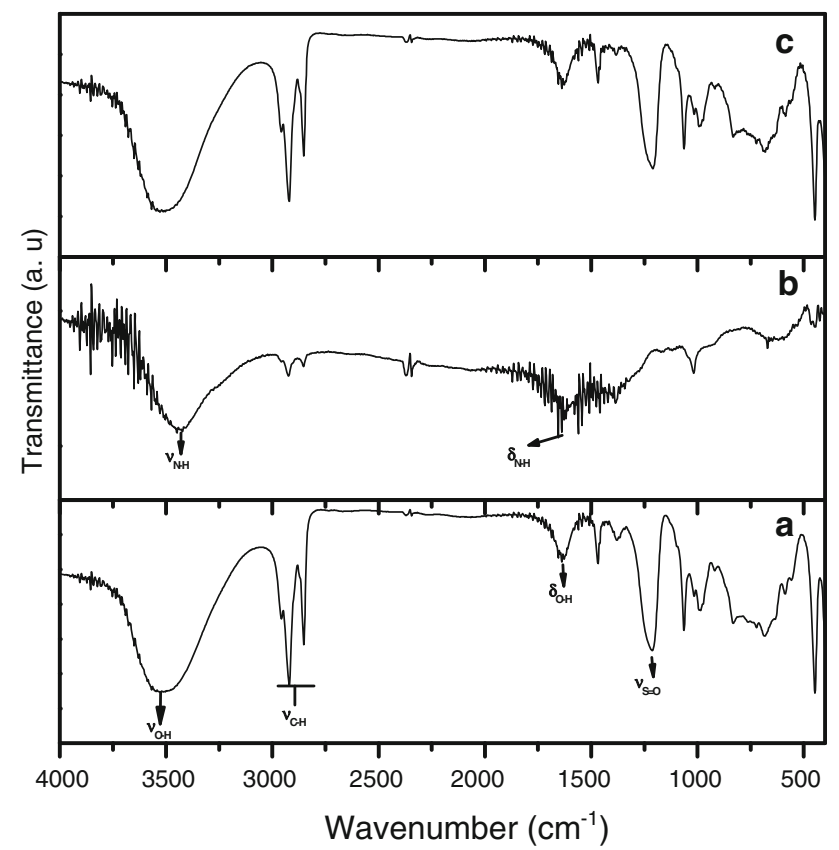

Fig. 2 IR spectra of Mg/Al-DS LDH (a), OA-capped Pt-nps (b) and Pt np-Mg/Al-DS LDH composite (c)
$3,500 \mathrm{~cm}^{-1}$ caused due to the overlapping of the $\mathrm{O}-\mathrm{H}$ and $\mathrm{N}-\mathrm{H}$ stretching bands.

Figure $3 \mathrm{a}, \mathrm{b}$ shows bright field TEM images of OAcapped Pt-nps and Pt-np-Mg/Al-DS LDH composite, respectively. The TEM image of Pt-nanoparticles showed spherical particles with an average particle size of $3 \mathrm{~nm}$, which is much lower than the values calculated using Scherrer's expression. This discrepancy in particle size arises as particle sizes measured by XRD (using Scherrer's equation) can be easily overestimated by even a small fraction of larger particles, which will contribute to a larger extent to the observed signal since the average measured by XRD is in fact weighted by the particle volume. TEM of the composite showed uniform distribution of Pt nanoparticles over the LDH matrix and the layered structure of the $\mathrm{Mg} / \mathrm{Al}-\mathrm{LDH}$ is intact. Selected area electron diffraction (SAED) patterns of the platinum nanoparticles (Fig. 3c) show characteristic features of platinum (Ha et al. 2011) and the indices are as mentioned in the figure. The SAED pattern of the composite (Fig. 3d) showed diffuse rings due to platinum along with the bright spots due to $\mathrm{Mg} / \mathrm{Al} \mathrm{LDH}$ that appears as a distorted hexagon (Abdelouas et al. 1994). The presence of Pt-nanoparticles in the Mg/Al-LDH matrix is further supported from the energy dispersive $\mathrm{X}$-ray spectrum (EDS) of the Pt-np-Mg/Al-DS LDH composite shown in Fig. 4. Peaks due to platinum, magnesium and aluminum are seen and peaks due to copper are due to the grid on which the sample was coated.

When the LDH is dispersed in 1-butanol, the solvent molecules enter the interlayer region leading to high degree swelling and delamination of the metal hydroxide layers. The delaminated colloidal dispersion is mixed with preformed oleylamine capped Pt-nanoparticles and the LDH layers are restacked along with Pt-nanoparticles by solvent evaporation to get a composite that is evident from the PXRD pattern (Fig. 1c). An enlarged inset clearly legitimates reflections due to Pt nanoparticles present along with the ' $a b$ ' plane reflections of the LDHs. Use of delaminated layers for composite preparation is essential as it facilitates easy mixing of the components yielding composite with uniform distribution of nanoparticles in the LDH matrix as evident in the TEM image of the composite (Fig. 3b). The incorporation of the Pt nanoparticles into the interlayer regions of the LDH is supported by the increase in the average interlayer distance of the composite by $\sim 4 \AA$. A very small increase in the average interlayer distance of the composite when compared to that of the pristine LDH is due to very small amounts of Pt nanoparticles (1:10 weight ratio) used for composite preparation. Increase in the amount of the nanoparticles in such a composite leads to a corresponding increase in the interlayer distance of the layered solid has already been reported. Moreover, the differently shaded $\mathrm{Pt}$ nanoparticles in the TEM of the composite (Fig. 3b) is due to 
Fig. 3 Bright field TEM images and SAED pattern of OA-capped Pt-nps (a, c) and Ptnp-Mg/Al-DS LDH composite $(\mathbf{b}, \mathbf{d})$
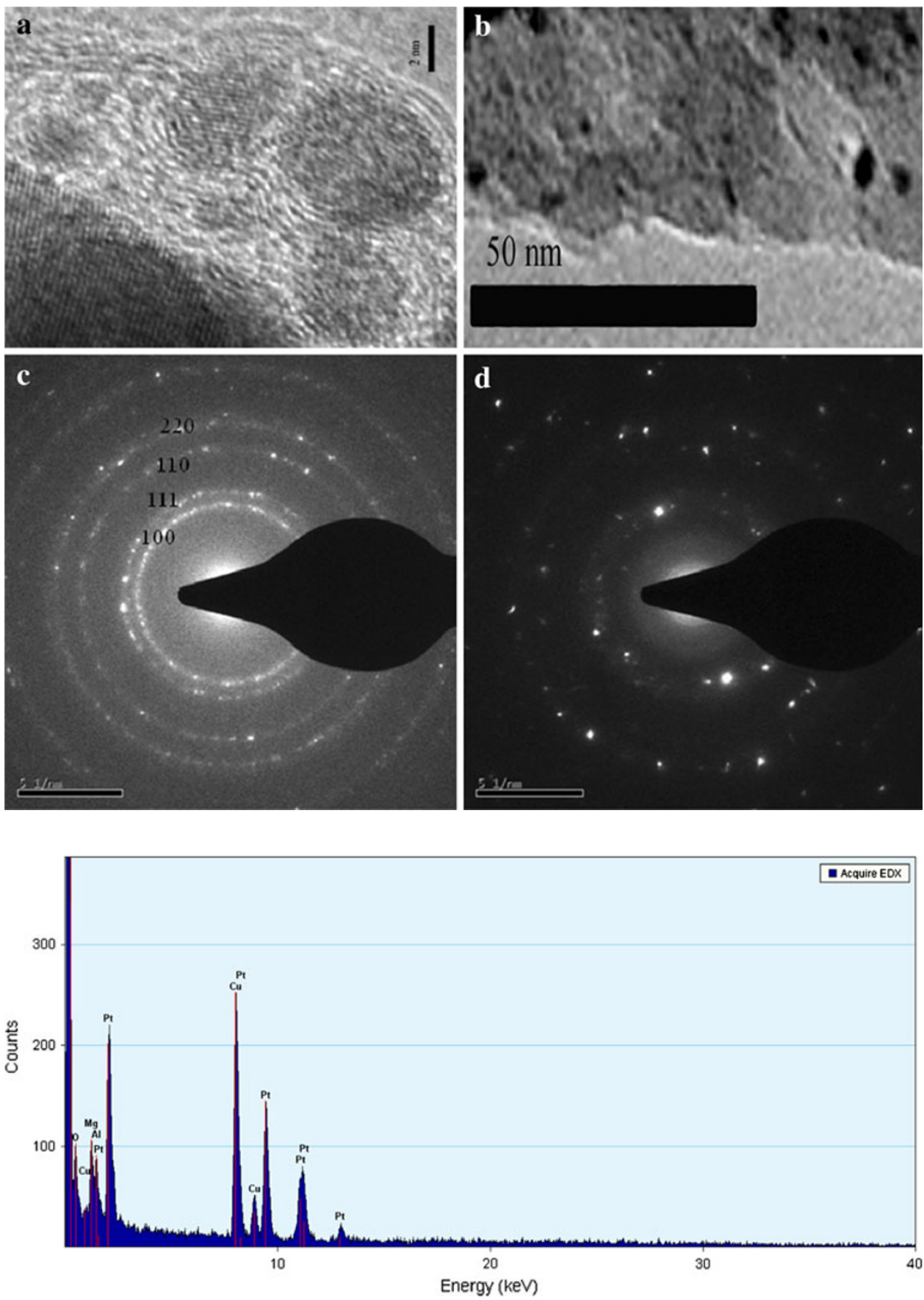

Fig. 4 Energy dispersive X-ray spectrum of Pt-np-Mg/Al-DS LDH composite the presence of the Pt nanoparticles present at various depths in the un-exfoliated LDH matrix. The technique employed for the synthesis of the composite can be used for other than $\mathrm{Mg} / \mathrm{Al} \mathrm{LDH}$ systems and also for other nanoparticles to suit particular application/s.

\section{Conclusion}

A general route for synthesis of noble metal nanoparticle intercalated layered solid composite was proposed taking the synthesis of Mg/Al-DS LDH supported Pt-nanoparticle composite as a specific example. The composite was prepared by restacking the delaminated $\mathrm{Mg} / \mathrm{Al}-\mathrm{DS} \mathrm{LDH}$ in the presence of preformed oleylamine capped Pt-nanoparticles in 1-butanol. The delamination-restacking technique employed can be applied to other layered solid-nanoparticle systems of various compositions.

Acknowledgments This work was funded by DST, New Delhi. The authors thank Indian Institute of Science for transmission electron microscopy and energy dispersive X-ray facilities. 
Open Access This article is distributed under the terms of the Creative Commons Attribution License which permits any use, distribution, and reproduction in any medium, provided the original author(s) and the source are credited.

\section{References}

Abdelouas A, Crovisier JL, Lutze W, Fritz B, Mosser A, Müller R (1994) Formation of hydrotalcite-like compounds during R7T7 nuclear waste glass and basaltic glass alteration. Clays Clay Miner 42:526-533

Amstad E, Gillich T, Bilecka I, Textor M, Reimhult E (2009) Ultrastable iron oxide nanoparticle colloidal suspensions using dispersants with catechol-derived anchor groups. Nano Lett 9:4042-4048

Anumol EA, Kundu P, Deshpande PA, Madras G, Ravishankar N (2011) New insights into selective heterogeneous nucleation of metal nanoparticles on oxides by microwave-assisted reduction: rapid synthesis of high-activity supported catalysts. ACS Nano 5:8049-8061

Basile F, Fornasari G, Gazzano M, Vaccari A (2000) Synthesis and thermal evolution of hydrotalcite-type compounds containing noble metals. Appl Clay Sci 16:185-200

Belova V, Möhwald H, Shchukin DG (2008) Sonochemical intercalation of preformed gold nanoparticles into multilayered clays. Langmuir 24:9747-9753

Choudary BM, Madhi S, Chowdari NS, Kantam ML, Sreedhar B (2000) Layered double hydroxide supported nanopalladium catalyst for Heck-, Suzuki-, Sonogashira-, and Stille-type coupling reactions of chloroarenes. J Am Chem Soc 124:1412714136

Gérardin C, Kostadinova D, Sanson N, Francova D, Tanchoux N, Tichit D, Coq B (2005) New nanoparticle/LDH composite materials as precursors of supported metal catalysts. Stud Surf Sci Catal 156:357-362

Granqvist CG (2007) Transparent conductors as solar energy materials: a panoramic review. Sol Energy Mater Sol Cell 91:1529-1598

Guo Y, Zhang H, Zhao L, Li G-D, Chen J-S, Xu L (2005) Synthesis and characterization of $\mathrm{Cd}-\mathrm{Cr}$ and $\mathrm{Zn}-\mathrm{Cd}-\mathrm{Cr}$ layered double hydroxides intercalated with dodecyl sulfate. J Solid State Chem 178:1830-1836

Ha H-W, Kim IY, Hwang SJ, Ruoff RS (2011) One-pot synthesis of platinum nanoparticles embedded on reduced graphene oxide for oxygen reduction in methanol fuel cells. Electrochem Solid State Lett 14:B70-B73

Habibi B, Delnavaz N (2010) Electrocatalytic oxidation of formic acid and formaldehyde on platinum nanoparticles decorated carbon-ceramic substrate. Int J Hydrog Energy 35:8831-8840

Halder A, Ravishankar N (2006) Gold nanostructures from cubeshaped crystalline intermediates. J Phys Chem B 110:6595-6600

Hibino T, Jones W (2001) New approach to the delamination of layered double hydroxides. J Mater Chem 11:1321-1323

Huu CP, Keller N, Ledoux MJ, Charbonniere LJ, Ziessel R (2000) Carbon nanofiber supported palladium catalyst for liquid-phase reactions. An active and selective catalyst for hydrogenation of $\mathrm{C}=\mathrm{C}$ bonds. Chem Commun 19:1871-1872

Jobbágy M, Regazzoni AE (2004) Delamination and restacking of hybrid layered double hydroxides assessed by in situ XRD. J Colloid Interf Sci 275:345-348

Kazanski VB, Borovkov VY, Serykh AI, Figuéras F (1997) Diffuse reflectance IR study of noble metals supported on basic carriers. Part I: Pt supported on Al-Mg hydrotalcite. Catal Lett 49:35-41
Komiyama M (1985) Design and preparation of impregnated catalysts. Catal Rev 27:341-372

Lerf A, Schöllhorn R (1977) Solvation reactions of layered ternary sulfides $\mathrm{A}_{x} \mathrm{TiS}_{2}, \mathrm{~A}_{x} \mathrm{NbS}_{2}$, and $\mathrm{A}_{x} \mathrm{TaS}_{2}$. Inorg Chem 16:2950-2956

Liu F, Piao Y, Choi KS, Seo TS (2012) Fabrication of free-standing graphene composite films as electrochemical biosensors. Carbon $50: 123-133$

Ma R, Sasaki T (2010) Nanosheets of oxides and hydroxides: ultimate 2D charge-bearing functional crystallites. Adv Mater 22:50825104

MacPhail RA, Strauss HL, Snyder RG, Elliger CA (1984) Carbonhydrogen stretching modes and the structure of n-alkyl chains. 2 . Long, all-trans chains. J Phys Chem 88:334-341

Nazar LF, Liblong SW, Yin XT (1991) Aluminum and gallium oxidepillared molybdenum oxide $\left(\mathrm{MoO}_{3}\right)$. J Am Chem Soc 113:5889-5890

Nethravathi C, Harichandran G, Shivakumara C, Ravishankar N, Rajamathi M (2005) Surfactant intercalated $\alpha$-hydroxides of cobalt and nickel and their delamination-restacking behavior in organic media. J Colloid Interf Sci 288:629-633

Nosaka Y (2011) Solar cells and photocatalysts. Compr Nanosci Technol 1:571-605

Pagano MA, Forano C, Besse J-P (2000) Delamination of layered double hydroxides by use of surfactants. Chem Commun 1:91-92

Papp S, Szücs A, Dékány I (2001) Preparation of $\mathrm{Pd}^{0}$ nanoparticles stabilized by polymers and layered silicate. Appl Clay Sci 19:155-172

Peralta MA, Zanuttini MS, Querini CA (2011) Activity and stability of $\mathrm{BaKCo} / \mathrm{CeO}_{2}$ catalysts for diesel soot oxidation. Appl Catal B Environ 110:90-98

Rajamathi JT, Ravishankar N, Rajamathi M (2005) Delaminationrestacking behaviour of surfactant intercalated layered hydroxy double salts, $\mathrm{M}_{3} \mathrm{Zn}_{2}(\mathrm{OH})_{8}(\operatorname{surf})_{2} \cdot 2 \mathrm{H}_{2} \mathrm{O} \quad[\mathrm{M}=\mathrm{Ni}, \quad \mathrm{Co} \quad$ and surf $=$ dodecyl sulphate (DS), dodecyl benzene sulphonate (DBS)]. Solid State Sci 7:195-199

Rajamathi JT, Ahmed MF, Ravishankar N, Nethravathi C, Rajamathi M (2009) Anionic clay-Pt metal nanoparticle composite through intercalation of hexachloroplatinate in nickel zinc hydroxysalt. Solid State Sci 11:1270-1273

Smith DD, Snow LA, Sibille L, Ignont E (2001) Tunable optical properties of metal nanoparticle sol-gel composites. J Non-Cryst Solids 285:256-263

Snyder RG, Strauss HL, Elliger CA (1982) Carbon-hydrogen stretching modes and the structure of $n$-alkyl chains. 1. Long, disordered chains. J Phys Chem 86:5145-5150

Taing J, Cheng MH, Hemminger JC (2011) Photodeposition of Ag or Pt onto $\mathrm{TiO}_{2}$ nanoparticles decorated on step edges of HOPG. ACS Nano 5:6325-6333

Trifiro F, Vaccari A (1996) Comprehensive supramolecular chemistry, vol 7. Pergamon Press, Oxford

Trudeau ML (2007) Nanostructured materials for gas reactive applications. In: Carl C. Koch (ed) Nanostructured materials: processing, properties and applications, 2nd Edition. William Andrew Inc., pp 365-437

Venugopal BR, Ravishankar N, Perrey CR, Shivakumara C, Rajamathi M (2006a) Layered double hydroxide-CdSe quantum dot composites through colloidal processing: effect of host matrixnanoparticle interaction on optical behavior. J Phys Chem B 110:772-776

Venugopal BR, Shivakumara C, Rajamathi M (2006b) Effect of various factors influencing the delamination behavior of surfactant intercalated layered double hydroxides. J Colloid Interf Sci 294:234-239

Walker GF (1960) Macroscopic swelling of vermiculite crystals in water. Nature 187:312-313 
Wang S, Choi D-G, Yang S-M (2002) Photocatalytic hydrogen evolution from water on nanocomposites incorporating cadmium sulfide into the interlayer. J Phys Chem B 106:12227-12230

Warren BE, Bodenstein P (1965) The diffraction pattern of fine particle carbon blacks. Acta Crystallogr 18:282-286

Wyckoff RWG (1963) Crystal structures, vol 1, 2nd edn. Interscience Publishers, New York, pp 7-83

Xu X, Zhang F, Xu S, He J, Wang L, Evans DG, Duan X (2009) Template synthesis of nanoparticle arrays of CdS in transparent layered double hydroxide films. Chem Commun 48:7533-7535

Yamamoto N, Okuhara T, Nakato T (2001) Intercalation compound of $\mathrm{VOPO}_{4} \cdot 2 \mathrm{H}_{2} \mathrm{O}$ with acrylamide: preparation and exfoliation. J Mater Chem 11:1858-1863
Yang M-H, Qu F-L, Lu Y-S, Shen G-L, Yu R-Q (2008) In situ chemical reductive growth of platinum nanoparticles on glass slide for the mass fabrication of biosensors. Talanta 4:831-835

Yeung KL, Sebastian JM, Varma A (1997) Mesoporous alumina membranes: synthesis, characterization, thermal stability and nonuniform distribution of catalyst. J Membr Sci 131:9-28

Zhang J, Xu H, Jin X, Ge Q, Li W (2005) Characterizations and activities of the nano-sized $\mathrm{Ni} / \mathrm{Al}_{2} \mathrm{O}_{3}$ and $\mathrm{Ni} / \mathrm{La}-\mathrm{Al}_{2} \mathrm{O}_{3}$ catalysts for $\mathrm{NH}_{3}$ decomposition. Appl Catal A Gen 290:87-96 